\title{
Neuroprotective Role of Nigella Sativa on Methamphetamine induced Hippocampal Injury in Male Albino Mice
}

\author{
Farhana Rajpar, Samreen Memon, Pushpa Goswami, Fayaz Ali Rajpar
}

\begin{abstract}
OBJECTIVE: To evaluate the neuroprotective effects of Nigella sativa in methamphetamine induced hippocampal injury.

METHODOLOGY: This Experimental study was conducted at Department of Anatomy, Liaquat University of Medical and Health Sciences (LUMHS), Jamshoro, in collaboration with Sindh Agriculture University Tandojam from April 2016 to September 2016 on sixty adult male mice of average $25-40 \mathrm{gms}$. All the animals were housed properly, fed on lab chow and tap water ad libitum. The mice were divided into group A (control), B, C and D were experimental groups. Group A was given normal saline orally at the volume of $1 \mathrm{ml} / \mathrm{kg}$. Group B animals were given METH at volume of $10 \mathrm{~mL} / \mathrm{kg}$ containing $10.0 \mathrm{mg} / \mathrm{kg}$ METH. Group C animals were given Kalonji extract at the volume of $3 \mathrm{mg} / \mathrm{ml}$ of extract, and Group D animals were given METH plus Kalonji extract at the same volume and dose as mentioned earlier. The animals were sacrificed by cervical dislocation after one week of last injection. Brain of each animal was removed, immersed in $10 \%$ formaldehyde solution for microscopic studies.

RESULTS: The weight of different groups at baseline was equal in all groups which is reduced at the end of study period. METH treated mice showing hyper cellularity of different layers, in contrast of N.S + METH treated mice showing marked decrease in cellularity of hippocampus.

CONCLUSION: The findings of above study shows neuroprotective effect of Nigella sativa against methamphetamine induced cell injury in hippocampus of mice model.
\end{abstract}

KEY WORDS: Hippocampus, Histomorphology, Immunohistochemistry, Methamphetamine, Nigella Sativa.

This article may be cited as: Rajpar F, Memon S, Goswami P, Rajpar FA. Neuroprotective Role of Nigella Sativa on Methamphetamine induced Hippocampal Injury in Male Albino Mice. J Liaquat Uni Med Health Sci. 2019;18(02):136-41. doi: 10.22442/jlumhs.191820616

\section{INTRODUCTION}

Methamphetamine (MA) is an illicit drug widely used for its potent psychostimulant effects. It is a drug of choice for abuse due to its low cost, easy availability and having long-lasting psychoactive effects ${ }^{1,2}$. MA notoriously caused more than $71 \%$ of global amphetamine-type stimulant (ATS) seizures ${ }^{3}$. It selectively damages the serotonergic and dopaminergic neurons of central nervous system (CNS) and increases the glial fibrillary acidic protein (GFAP) which is an index of gliosis following neuronal injury and drug induced toxicity ${ }^{4,5}$. MA induces neurotoxicity through different mechanisms; proposed mechanisms included apoptosis, DNA damage, inflammatory mediators, damage to blood brain barrier and neuronal over excitatory injury ${ }^{6,7}$. Previous studies also reported ischemic and MA induced injury of brain hippocampus in rat models ${ }^{8,9}$. Nigella sativa (kalonii) is a spicy herb with religious background and medicinal history. Historically, its use dates back to the Kingdom of Assyrians and Ancient Egyptians about 3,000 years ago ${ }^{10,11}$. Hobbenaghi (2014) et al reported that the NS exerted neuroprotective effects in hippocampus neurons in experimental rats with global cerebral ischemia-reperfusion injury. Thymoquinone (TQ) is the most active constituents of $\mathrm{N}$. sativa, attributes to therapeutic actions of $\mathrm{N}$. sativa. $\mathrm{TQ}$ is used as chemotherapeutic and chemo preventive agent in various disease ${ }^{12,13}$.

The purpose of this study was to evaluate neuroprotective effects of Nigella sativa in methamphetamine induced hippocampal injury as evidenced by histomorphology and immunohistochemistry of tissue sections of hippocampus.

\section{METHODOLOGY}

This Experimental study was conducted at Department of Anatomy, Liaquat University of Medical and Health Sciences (LUMHS), Jamshoro, in collaboration with Sindh Agriculture University Tandojam from April 2019 to September 2016. All animal procedures were conducted under animal 
protocol approved by Sindh Agriculture University Tando Jam. Sixty adult male mice of average 25-40gm body weight were selected. Sick mice, mice not feeding and female mice were excluded. All animals were housed in stainless steel cages equipped with feed containers and drinkers. They were provided food (lab chow) and tap water ad libitum. The light/dark cycle of 12 hours interval is maintained. The mice were divided in to four groups. Control Group A was given normal saline orally at the volume of $1 \mathrm{ml} / \mathrm{kg}$. Experimental Group B animals were given METH at volume of $10 \mathrm{~mL} / \mathrm{kg}^{3,9}$ containing $10.0 \mathrm{mg} / \mathrm{kg} \mathrm{METH}$. Experimental Group C animals were given Kalonji extract at the volume of $3 \mathrm{mg} / \mathrm{ml}$ of extract, and Experimental Group D animals were given METH plus Kalonji extract at the same volume and dose as mentioned earlier. The normal saline, METH and kalonji extract were given in 2 divided doses at the intervals of 8 hours in first three groups. However, the fourth group received the dose of kalonji extract 30 min before the METH.

Body weight and temperature were measured using digital thermometer, rectal temperature was measured before the first injection of METH and 1 hour after each successive drug injection up to 24 hours duration. If the temperature was found raised during the treatment, the animals were cool down by putting them in cages with ice. The animals were sacrificed by cervical dislocation after one week of last injection. Brain of each animal was removed, immersed in $10 \%$ formaldehyde solution, and fixed over night at $70^{\circ} \mathrm{C}^{12,14}$.

\section{Preparation of $\mathbf{N}$. sativa extracts}

The powdered seed $(50 \mathrm{~g})$ was boiled in $500 \mathrm{ml}$ boiling water for 15 min then mixture was filtered and concentrated under reduced pressure at $35^{\circ} \mathrm{C}^{12}$.

Brain Tissue Slicing and Staining was done as Hippocampal sections of $5 \mu \mathrm{m}$ thick were obtained by microtome, through ethyl alcohol and xylene series and embedded in paraffin blocks, stained with Hematoxylin and Eosin (H\&E).

Microphotography was done with all the photographs and measurements were carried out with the help of digital microscope with Digi pro software.

Immunohistochemistry was carried out with commercially available monoclonal antibody against glial fibrillary acidic protein, GFAP-Elisa Kit, USA was used for Immunohistochemistry. ${ }^{15}$

Pre-approved proforma was used to collect and document data during research.

Data was analyzed using SPSS version 22.
Quantitative and Qualitative variables were analyzed using analysis of variance, post-Hoc testing and Chi square test respectively. Statistical significance was taken as $p \leq 0.005$ (Confidence interval 95\%).

\section{RESULTS}

The present experimental study was conducted to investigate the neuroprotective effect of Nigella sativa on methamphetamine induced hippocampus injury in mice. Brain tissue sections were examined by $\mathrm{H}$ \& $\mathrm{E}$ staining and Immunohistochemistry.

Table I shows the weight of different groups at baseline and at the end of study period. At baseline, the weight of mice was equal in all groups. While at the end of study period, weight was reduced in group B (METH treated mice) $(p=0.001)$. Graph I shows the comparison of weight of different mice groups at baseline with weight at the end of study period.

Histomorphology in photomicrograph I show the changes in different layers of hippocampus in comparison with control group. In (1a) different areas of Hippocampus (1b) of METH treated mice showing hyper-cellularity of different layers, in (1c) section of N.S treated mice showing normal cellularity at hippocampus, in contrast (1d) section of N.S + METH treated mice showing marked decrease in cellularity of hippocampus (H \& Ex100).

The panels of Immunohistochemical sections in photomicrograph II were selected to show the changes of different layers of hippocampus in comparison with control group. In (2a) Tissue section of Immunohistochemical staining for Glial fibrillary acidic proteins (GFAP) of hippocampus showing its normal distribution (2b) of METH treated mice showing over expression (GFAP) of different layers of hippocampus, in (2c) section of N.S treated mice showing normal expression of (GFAP) at different layers of hippocampus, in contrast (2d) section of N.S $+\mathrm{METH}$ treated mice showing marked changes of hippocampus. (IHC x10)

The panels of histomorphology and immunohistochemistry of sections in photomicrograph III were selected to show the changes of different layers of hippocampus in comparison with control group. In (3a) $M$ ETH treated mice tissue section showing ventricular derangement/compression. (3b) section of N.S + METH treated mice showing reversal of ventricular damage, in (3c) IHC section METH treated mice showing necrotic lesion at hippocampus (IHC x10) in (3d) Histomorphological section of METH treated mice showing necrotic lesion at hippocampus. (H\&E x10) 


\section{PHOTOMICROGRAPH I: (1a-1d)}

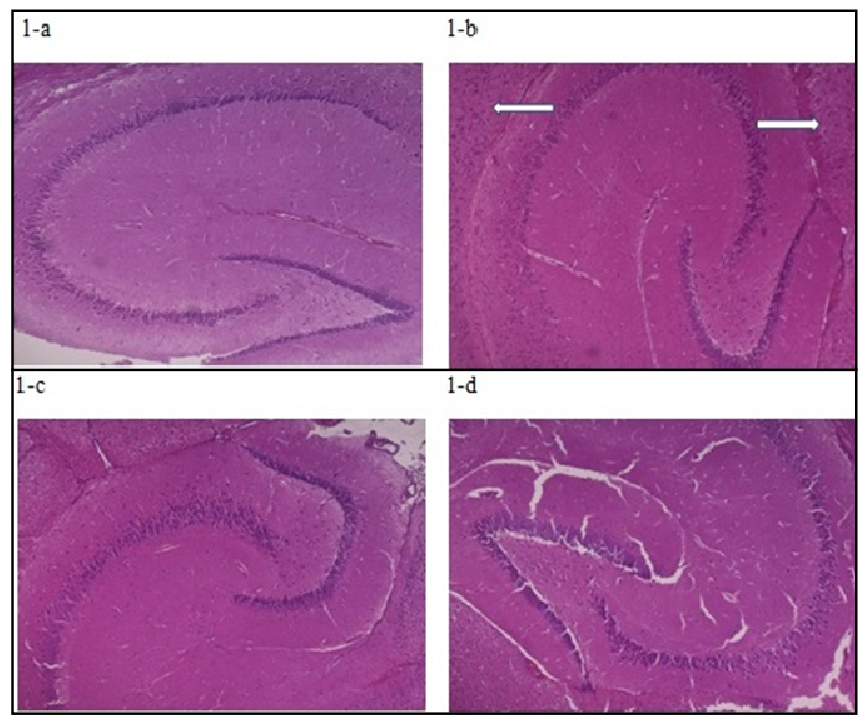

The panels in this photomicrograph were selected to show the changes of different layers of hippocampus in comparison with control group. In (1a) different areas of Hippocampus, the hippocampus (1b) of METH treated mice showing hyper cellularity of different layers, in (1c) section of N.S treated mice showing normal cellularity at hippocampus, In contrast (1d) section of N.S + METH treated mice showing marked decrease in cellularity of hippocampus. ( $H$ \& E x10).

\section{PHOTOMICROGRAPH II: (2a-2d)}

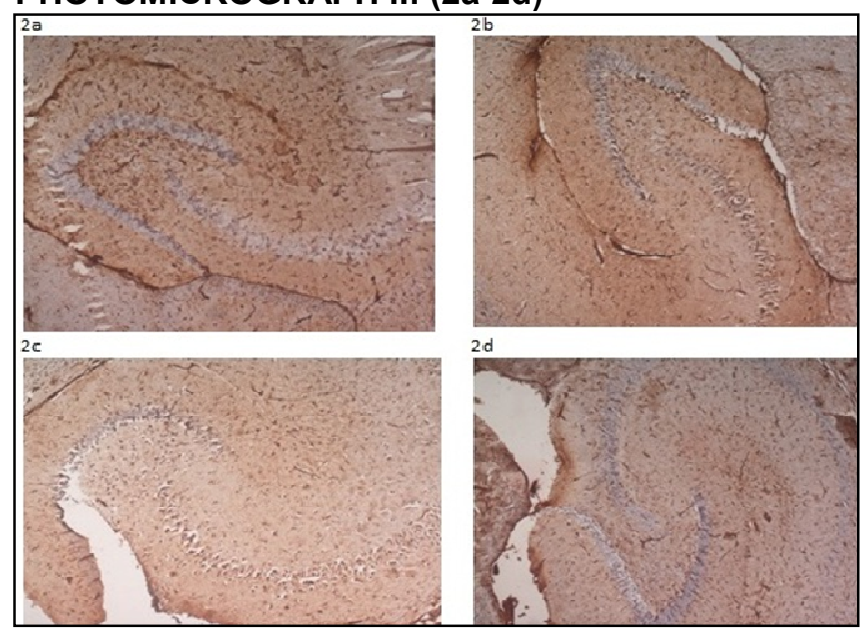

TABLE I: WEIGHT (GMS) OF MICE
The panels in this Immunohistochemical sections of this picture were selected to show the changes of different layers of hippocampus in comparison with control group. In (2a) Tissue section of Immunohistochemical staining for Glial fibrillary acidic proteins (GFAP) of hippocampus showing its normal distribution (2b) of METH treated mice showing over expression (GFAP) of different layers of hippocampus, In (2c) section of N.S treated mice showing normal expression of (GFAP) at different layers of hippocampus, In contrast (2d) section of N.S + METH treated mice showing marked changes of hippocampus. (IHC x10).

\section{PHOTOMICROGRAPH -III}

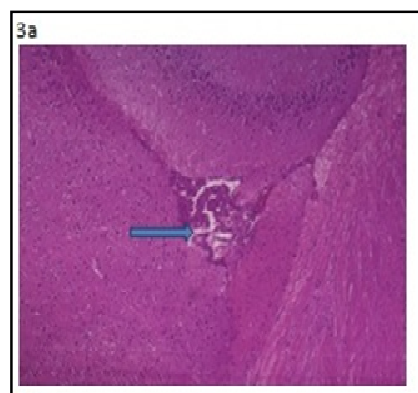

$3 c$
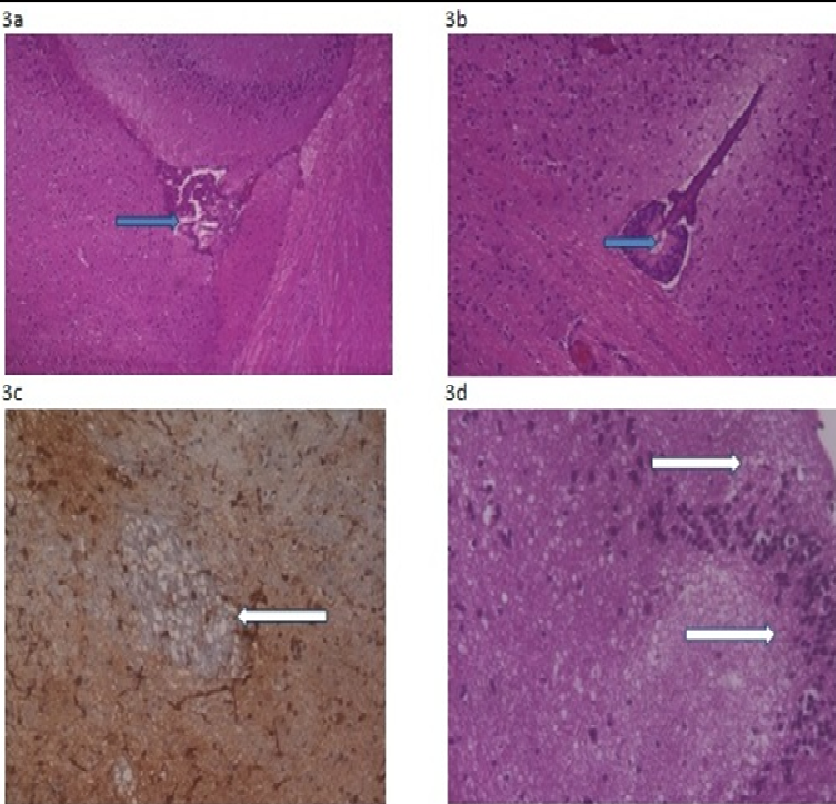

$3 d$

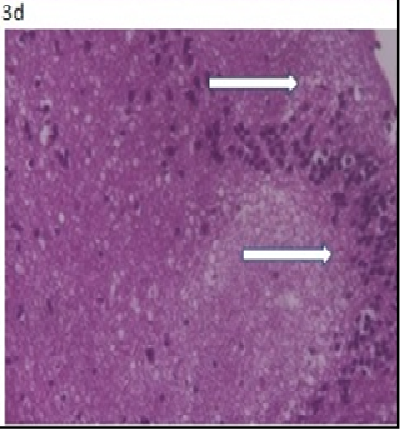

The panels in this section of this figure were selected to show the changes of different layers of hippocampus in comparison with control group. In (3a) M ETH treated mice tissue section showing ventricular derangement/compression. (3b)section of N.S+METH treated mice showing reversal of ventricular damage, In (3c) IHC section METH treated mice showing necrotic lesion at hippocampus. (IHC $\mathrm{x} 10$, ) In (3c) Histomorphologicalsection METH treated mice showing necrotic lesion at hippocampus. (H\&E x10)

\begin{tabular}{|c|c|c|c|c|c|c|}
\hline Groups & \multicolumn{3}{|c|}{ Weight at baseline } & \multicolumn{3}{|c|}{ Weight at the end of study } \\
\hline Group A. Control Mice & Mean & SD & $P$ value & Mean & SD & $P$ value \\
\hline Group B. Methamphetamine & 32.0 & 4.6 & \multirow{4}{*}{0.96} & 33.4 & 4.4 & \multirow{4}{*}{0.001} \\
\hline Group C. Kalonji extract & 32.1 & 4.5 & & 26.8 & 3.6 & \\
\hline \multirow{2}{*}{ Group D. Methamphetamine+ Kalonji extract } & 31.4 & 5.5 & & 32.4 & 5.4 & \\
\hline & 31.4 & 4.2 & & 29.6 & 4.16 & \\
\hline
\end{tabular}


GRAPH I: COMPARISON OF BODY WEIGHT OF MICE AT BASELINE AND END OF STUDY PERIOD

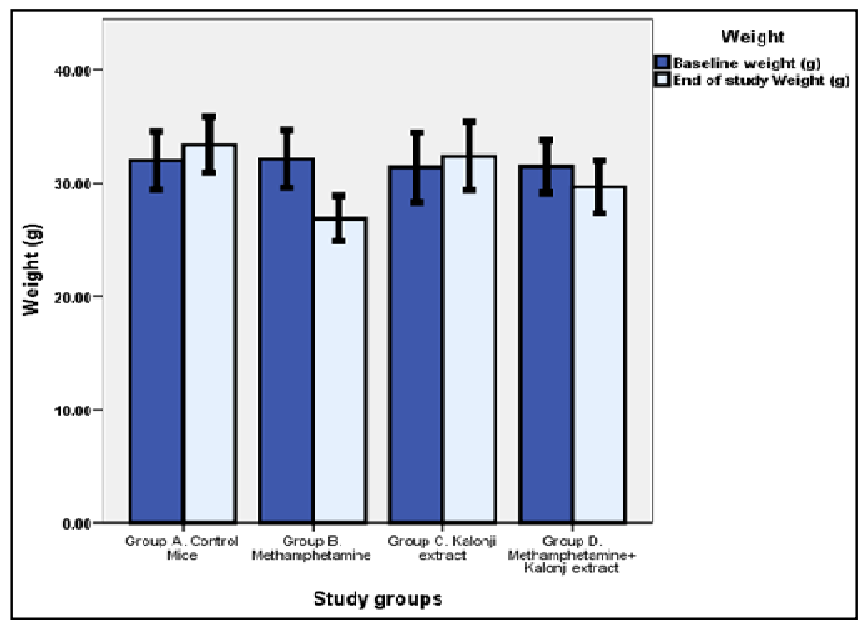

These findings show a neuroprotective effect of Nigella sativa against methamphetamine induced cell injury in hippocampus of mice model.

\section{DISCUSSION}

Many people take Methamphetamine(MA) due to its attention-enhancing effects. A literature search showed several studies on methamphetamine induced injury of brain hippocampus in rat models and its neuroprotective effects by Nigella sativa ${ }^{10,11,16}$.

The findings of present experimental study, conducted on 60 mice model, Brain tissue sections examined by $H$ \& $E$ staining and Immunohistochemistry are consistent with findings of other studies as well ${ }^{17,18}$.

A previous study has reported neuroprotective effects of NS on the chronic toluene induced neuronal injury at sub cellular levels. The changes of neuronal injury completely disappeared in the NS treated animals and histopathological examination showed reversal of cell injuries ${ }^{19}$.

Highly neuroprotective effect of $\mathrm{NS}$ and TQ was observed against toluene induced hippocampus injury by other researchers as we $\|^{20,21}$.

In present study, the methamphetamine treated mice showed neurodegenerative changes. Most damaging effect was shown by Astrocytosis (hypercellular glial tissue) and necrosis of different layers of hippocampus. While NS treated mice reversed the amphetamine induced neuronal injury. Ventricular injury was not found and cellularity was noted normal in NS treated hippocampus (Photomicrograph-3b). These findings are in support of above mentioned studies. Group D- mice received methamphetamine with Nigella sativa and were compared with Group
B-methamphetamine treated mice. Significant differences were observed between group $B$ and $D$. Overall the NS exerted significant neuroprotective effects against methamphetamine.

Another novel part of present study was the immunohistological examination as shown in Photomicrograph 02. Over expression of GFAP was not observed in the controls and NS + methamphetamine treated mice. On the contrary, a high expression of GFAP was noted in the group B- methamphetamine treated mice hippocampus.

Nigella sativa treated mice showed normal expression of GFAP as shown in Photomicrograph 2a. GFAP showed normal expression in various layers of hippocampus. Methamphetamine + Nigella sativa treated mice showed no abnormality in expression of GFAP as show in Photomicrographs 2c. Normal expression of GFAP was noted in all parts and layers of hippocampus in mice treated by Nigella sativa.

Methamphetamine induced mice showed a body weight reduction as shown in table 1 the finding is supported by previous studies ${ }^{16,17,22}$.

Thymoquinone (TQ) showed significant neuroprotective effects in hippocampal neurons in neurodegenerative effects of Alzheimer disease (AD), which is highly consistent with this study as Nigella sativa produced similar effects in the present study against methamphetamine induced injury ${ }^{22}$.

Another previous study has reported neuroprotective effects of TQ significantly against hippocampus injury in experimental animals by increasing anti-oxidant enzyme activity ${ }^{24}$.

From the above discussion and findings of histopathological and immunohistochemical analysis of hippocampus of mice of present study suggests a neuroprotective effect of Nigella sativa

\section{CONCLUSION}

The findings of above study shows neuroprotective effect of Nigella sativa against methamphetamine induced cell injury in hippocampus of mice model. Nigella sativa is commonly available herb can be used in clinical practice and will be beneficial for community at very affordable cost.

Ethical Permission: ERC approval letter of LUMHS No. LUMHS/REC/342 dated: 07-05-2015.

Conflict of interest: There was no any conflict of interest.

Funding: There was no any funding agency. 


\section{REFERENCES}

1. Maxwell JC, Brecht ML. Methamphetamine: here we go again? Addict Behav. 2011; 36(12):116873. doi: 10.1016/j.addbeh.2011.07.017.

2. United Nation Office on drugs and crime (UNODC). United Nations Publication; Vienna: 2013. World Drug Report 2013. (Sales No. E.13. $\mathrm{X} 1.6)$.

3. Castelli MP, Madeddu C, Casti A, Casu A, Casti $P$, Scherma $M$, et al. $\Delta 9$ - tetrahydro- cannabinol prevents methamphetamine-induced neurotoxicity. PLoS One. 2014; 9(5): e 98079. doi: 10.1371/ journal.pone.0098079.

4. LaVoie MJ, Card JP, Hastings TG. Microglial activation precedes dopamine terminal pathology in methamphetamine-induced neurotoxicity. Exp Neurol. 2004; 187(1):47-57.

5. Thomas DM, Dowgiert J, Geddes TJ, Francescutti -Verbeem D, Liu X, Kuhn DM. Microglial activation is a pharmacologically specific marker for the neurotoxic amphetamines. Neurosci Lett. 2004; 367(3):349-54.

6. Davidson C, Gow AJ, Lee TH, Ellinwood EH. Methamphetamine neurotoxicity: necrotic and apoptotic mechanisms and relevance to human abuse and treatment. Brain Res Brain Res Rev. 2001; 36(1): 1-22.

7. Marshall JF, O'Dell SJ. Methamphetamine influences on brain and behavior: Unsafe at any speed? Trends Neurosci. 2012; 35(9): 536-45. doi: 10.1016/j.tins.2012.05.006.

8. Ricoy UM, Martinez Jr. JL. Local Hippocampal Methamphetamine-Induced Reinforcement. Front Behav Neurosci. 2009; 3: 1-10. doi: 10.3389/ neuro.08.047.2009

9. Deng X, Jayanthi S, MCcoy MT, Ladenheim B, Rothman RK, Cadet JL. Methamphetamine injections cause widespread increases in caspase -8 expression in the mouse brain. J Drug Alco Res. 2013; 2:1-7. doi:10.4303/jdar/235648

10. Khan MLA. Kalonji (Nigella Sativa) Islamic voice 2009; 1308(152): 1-2. Available from: http:// www.islamicvoice.com/august.99/tibb.htm\#KAL

11. Naz H. Nigella sativa: the miraculous herb. Pak J Biochem Mol Biol. 2011; 44(1): 44-48.

12. Hosseinzadeh $H$, Jaafari MR, Khoei AR, Rahmani $M$. Anti-ischemic Effect of Nigella sativa L. Seed in Male Rats. IJPR. 2006; 5(1): 53-8. doi: 10.22037/ ijpr.2010.653.

13. Arifin WN, Zahurdin WM. Sample size calculation in animal studies using resource equation approach. Malays J Med Sci. 2017; 24(5): 101105. doi: 10.21315/mjms2017. 24 .5.11.

14. Hobbenaghi R, Javanbakht J, Sadeghzadeh SH, Kheradmand D, Abdi FS, Jaberi $M H$, et al. Neuroprotective effects of Nigella sativa extract on cell death in hippocampal neurons following experimental global cerebral ischemia-reperfusion injury in rats. J Neurol Sci. 2014; 337(1-2):74-9. doi: 10.1016/j.jns.2013.11.019.

15. Amin SN, Younan SM, Youssef MF, Rashed LA, Mohamady I. A histological and functional study on hippocampal formation of normal and diabetic rats. F1000 Res. 2013; 2:151. doi: 10.12688/ f1000research.2-151.v1

16. Tahraoui A, El-Hilaly J, Israili ZH, Lyoussi B. Ethnopharmacological survey of plants used in the traditional treatment of hypertension and diabetes in south-eastern Morocco (Errachidia province). J Ethnopharmacol. 2006; 110(1):105117.

17. Khazdair MR. The Protective Effects of Nigella sativa and its Constituents on Induced Neurotoxicity. J Toxicol. 2015; Article ID 841823:1 -7. doi:10.1155/2015/841823.

18. Kanter M. Protective effects of nigella Sativa on the neuronal injury in frontal cortex and brainstem after chronic toluene exposure. Neurochem Res. 2008; 33(11): 2241-9. doi: 10.1007/s11064-0089702-0.

19. Kanter M. Nigella sativa and derived thymoquinone prevents hippocampal neurodegeneration after chronic toluene exposure in rats. Neurochem Res. 2008; 33(3): 579-88.

20. Kanter M. Protective effects of thymoquinone on the neuronal injury in frontal cortex after chronic toluene exposure. J Mol Histol. 2011; 42 (1): 3946. doi: 10.1007/s10735-010-9305-3.

21. Benhaddou-Andaloussi A, Martineau LC, Spoor D, Vuong T, Leduc C, Joly E, et al. Antidiabetic Activity of Nigella sativa. Seed Extract in Cultured Pancreatic $\beta$-cells, Skeletal Muscle Cells, and adipocytes. Pharmaceut Biol. 2008; 46(1-2): 96-104. doi: 10.1080/13880200701734810

22. Hayashizaki S, Hiraj S, Ito $\mathrm{Y}$, Honda $\mathrm{Y}$, Arime $\mathrm{Y}$, Sora I, et al. Methamphetamine increases locomotion and dopamine transport activity in dopamine d5 receptor-deficient Mice. PLoS One. 2013; 8(10): e75975. doi: 10.1371/journal.pone. 0075975 . 
23. Alhebshi $\mathrm{AH}$, Gotoh M, Suzuki I. Thymoquinone protects cultured rat primary neurons against amyloid $\beta$-induced neurotoxicity. Biochem Biophys Res Commun. 2013; 433(4):362-67. doi: 10.1016/ j.bbrc.2012.11.139.
24. Al-Majed AA, Al-Omar FA, Nagi MN. Neuroprotective effects of thymoquinone against transient forebrain ischemia in the rat hippocampus. Eur $\mathrm{J}$ Pharmacol. 2006; 14; 543(1-3):40-7.

AUTHOR AFFILIATION:

Dr. Farhana Rajpar

Assistant Professor, Department of Anatomy Liaquat University of Medical and Health Sciences (LUMHS), Jamshoro, Sindh-Pakistan.

Dr. Samreen Memon

Professor, Department of Anatomy

LUMHS, Jamshoro, Sindh-Pakistan.

Dr. Pushpa Goswami (Corresponding Author) Associate Professor, Department of Anatomy LUMHS, Jamshoro, Sindh-Pakistan.

Email: pushparamesh1998@gmail.com

Dr. Fayaz Ali Rajpar

Medical Officer, SESSI Sindh, Pakistan. 